\title{
TEKNIK DASAR MENGGUNAKAN VIDEOGRAFI DI DUNIA BROADCASTING
}

\author{
Sugeng Widada ${ }^{1}$ \\ Adi Kusuma Widya Tama ${ }^{2}$ \\ Muhamad Rendi Purnama ${ }^{3}$ \\ Dosen STMIK Raharja ${ }^{1,2}$, STMIK Raharja Jurusan Sistem Informasi ${ }^{3}$ \\ Jl. Jendral Sudirman No. 40, Modern Cikokol, Tangerang \\ Email : sugeng.widada@raharja.info ${ }^{1}{ }^{1}$, adi.kusuma@raharja.info $^{2}{ }^{2}, \underline{\text { rendi@raharja.info }}^{31}$
}

\begin{abstract}
ABSTRAK
Sebagai industri kreatif yang berbasis teknologi, maka banyak pekerjaan di sini yang butuh kreativitas. Namun tetap harus menguasai sistem peralatan atau teknologi yang digunakan alat seperti videografi banyak di masyarakat yang menggunakan agar hasil video lebih maksimal. dengan teknologi digital, juga memungkinkan untuk melakukan seтua dari berbagai fungsi sendiri dan menghasilkan kualitas yang memuaskan. Sebuah peralatan elektronis dapat merekam gambar dalam jumlah tertentu hingga nantinya terdapat ilusi gerak dari gambar yang direkamnya.

Kata kunci : videografi, video, kamera.
\end{abstract}

\begin{abstract}
Along with the changing times and by utilizing the latest technological sophistication videography can be enjoyed in various ways and any variety of formats offered by technology experts in the world.There are currently 2 types of videos are available, namely analog and digital.A videographer categorized or categorize themselves into two, namely the amateur videographer and professional videographer.Amateur or professional, in fact is only the term and sheer status. Unfortunately, it seems there is a presumption of amateur videographer if the result is definitely not good.And because the feel just amateurs, someone feel legitimate only if the video footage is not good.Instead, there is a presumption that a professional videographer can certainly produce good images.
\end{abstract}

Keywords: videography, video, camera.

\section{PENDAHULUAN}

Garis imajiner merupakan garis pembatas kanan dan kiri 180 derajat. Jika garis ini dilanggar atau crossing the line maka dapat merusak continuitas yang telah terbentuk. Metode ini berlaku untuk penggunaan pada produksi single kamera atau multi kamera dan erat kaitannya dengan proses editing. Sehingga Menggerakkan badan kamera secara horizontal, tetapi tidak merubah posisi kedudukan kamera. Gerakan panning terdiri dari dua gerakan berdasarkan arah geraknya yaitu Pan Kanan dan Pan Kiri.

\section{RUMUSAN MASALAH}

Sebuah karakter video sama halnya dengan karakter seorang perempuan ada yang cantik dan manis, video yang cantik pada saat melihat pertama akan mengensankan, namun kita tidak akan penasaran lagi untuk mengulang memutar video tersebut. sedangkan video yang manis akan selalu menjadi video yang akan selalu tertarik untuk diulang terus menerus untuk diputar, kita tidak akan bosan melihatnya. Maka dari itu banyak masyarakat blm mengetahui angle kamera dan pergerakan kamera di sini akan menggali semua tentang kamera video. 
Agar masyarakat mengetahui pergerakan kamera. video adalah sebuah kumpulan gambargambar yang disatukan, sehingga mempunyai alur yang sesuai dengan apa yang kita ingin kan. dengan mengetahui teknik-teknik dalam pengambilan gambar, maka untuk langsung terjun kelapangan kita tidak akan canggung lagi, angel apa yang ingin kita ambil.

\section{LANDASAN TEORI}

Pengertian Videografi

Sebuah alat bantu audio visual yang berarti bahan atau alat yang dipergunakan dalam situasi belajar untuk membantu tulisan dan kata yang diucapkan dalam menularkan pengetahuan, sikap, dan ide.

\section{Motifasi Membuat Film}

Mengsarap sebuah film berdurasi pendek sekalipun tidak semudah memberikan telapak tangan, apalagi hanya dengan membaca berbagai teori pembuatan film ini lalu kita dapat menghasilkan sebuah karya film yang baik. Menggarap film membutuhkan jam terbang yang cukup, sekaligus diimbangi dengan seringnya mengkuti praktek produksi.

\section{Film Dokumenter (Documentary Films)}

Kisah nyata dan di buat ulang menjadi sebuah film melalui reka ulang dari kisah nyata tersebut.

\section{Film Cerita Pendek (Short Films)}

Film yang biasanya di buat oleh mahasiswa film ini berbentuk fiksi durasi yang di buat untuk film cerita pendek tersebut rata-rata 60 menit.

\section{Film Cerita Panjang (Feature-length Films)}

Film yang di putar di layar lebar karena film tersebut melebihi durasi dari 60 menit dan di lihat oleh seluruh dunia.

\section{Film Profile Perusahaan (Corporate Profile)}

Film yang di buat untuk mempromosikan sebuah perusahaan melalui video yang nantina akan di pasarkan ke masyarakat luas.

\section{Film Iklan Televisi (TV Comersial)}

Suatu ikaln yang memesarkan produk jasa dengan durasi singkat tetapi di dalam iklan tersebut lebih jelas untuk memasarkan produk tersebut.

\section{Film Program Televisi (TV Programme)}

Film yang di produksi oleh PH (Production House) dan hasil tersebut di tayangkan melalui stasiun Televisi.

\section{Video Clip ( Music Video)}

Acata khusus musik yang di buat oleh produser musik dan di sebarkan melalui televisi.

\section{Program Acara Drama / Fiksi}

Sebuah format acara televisi yang diproduksi dan diciptakan melalui proses imajinasi kreatif dari kisah-kisah drama atau fiksi yang direkayasa dan dikreasi ulang. 
1. Legenda adalah cerita rakyat dari zaman dahulu yang berkaitan dengan peristiwaperistiwa sejarah.

2. Drama lepas / film yaitu drama yang terdiri dari satu menit.

3. Drama spesial / sinetron yaitu drama yang terdiri atas beberapa episode, dimana satu episode dengan episode lainnya berhubungan atau bersambungan.

4. Komedi yaitu program televisi mengenai cerita dramatik berkarakter ringan dan berisi humor, adegan-adenganya menyenangkan dan menghibur.

\section{Program acara non drama / non fiksi}

Sebuah format acara televisi yang diproduksi dan diciptakan melalui proses pengolahan imajinasi kreatif dari realitas kehidupan sehari-hari tanpa harus menginterpretasi ulang dan tanpa harus menjadi dunia khayalan.

1. Talk Show yaitu program acara televisi mengenai perbincangan, percakapan orang per orang atau beberapa orang tentang suatu masalah yang sedang hangat dibicarakan.

2. Video klip yaitu format acara yang mengenai lagu-lagu yang diperdengarkan kepada audiences dan tujuannya adalah untuk mempromosikan lagu tersebut.

3. Quiz yaitu acara yang menampilkan suatu permainan dengan cara dan hadiah tertentu, acara ini juga menyampaikan seorang tokoh atau para penontonnya sebagai peserta quiz.

4. Variety musik yaitu acara yang berisi berbagai ragam jenis lagu dan dipandu oleh satu atau dua orang presenter. Dalam program ini disisipi leluconan, sulap atau acara lainnya agar musik tidak membosankan dipanggung (stage) studio.

\section{Aspect Ratio}

Rasio aspek adalah hubungan lebar gambar video dibandingkan dengan tinggi badannya. Dua aspek rasio yang paling umum adalah 4: 3, juga dikenal sebagai 1.33: 1 atau fullscreen, dan 16: 9, juga dikenal sebagai 1.78: 1 atau layar lebar. (Format rasio aspek yang lebih besar digunakan dalam industri film bergerak.)
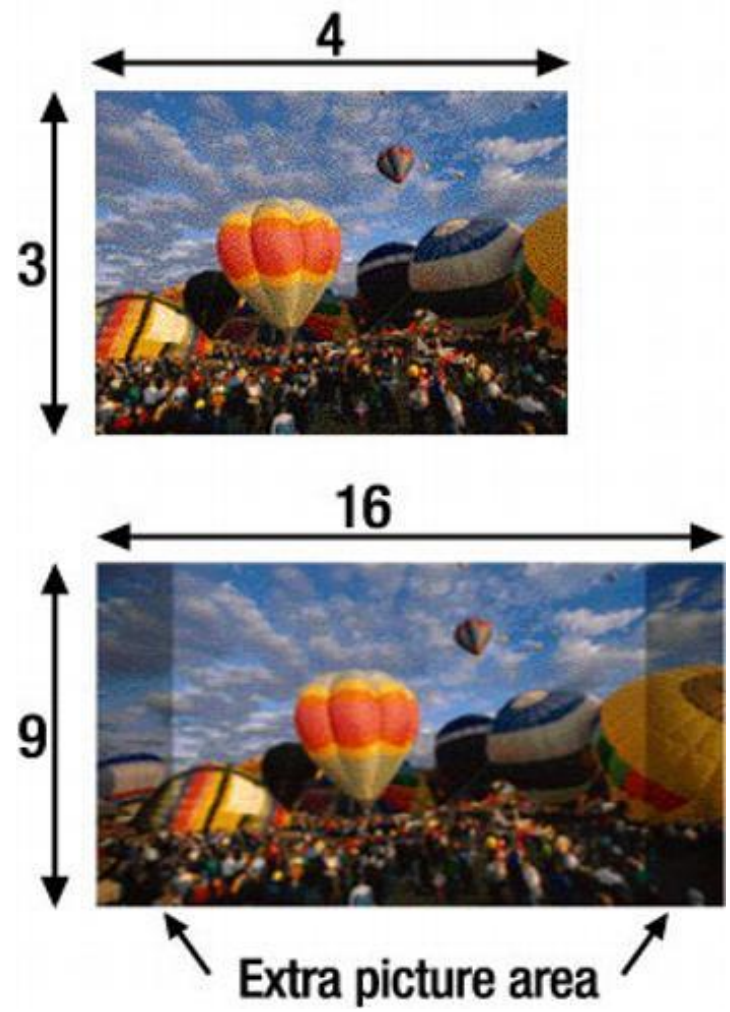

Gambar 1 Aspect Ratio 


\section{Frame Size atau resolusi dari sebuah gambar}

Lebar dan tinggi frame video disebut dengan frame size. Sedangkan untuk mengukur gambar menggunakan satuan pixel, atau dalam Audio Video frame size disebut resolusi sebuah frame. Makin tinggi sebuah resolusi dalam suatu gambar, maka semakin besar pula kebutuhan memori untuk membaca sebuah informasi tersebut.

\begin{tabular}{|c|c|c|c|}
\hline System & Frame Rate & Frame Size & Keperluan \\
\hline NTSC & 30 & 320 Pixel X 240 Pixel & VCD \\
\hline PAL & 25 & 352 Pixel X 288 Pixel & VCD \\
\hline NTSC & 30 & 720 Pixel X 480 Pixel & DVD \\
\hline PAL & 25 & 720 Pixel X 576 Pixel & DVD \\
\hline NTSC & 30 & 1440 Pixel X 1080 Pixel & HDTV \\
\hline PAL & 25 & 1440 Pixel X 1080 Pixel & HDTV \\
\hline
\end{tabular}

Gambar 2. Frame Size atau resolusi dari sebuah gambar

\section{KAMERA DAN JENIS KAMERA}

\section{Kamera Obscura}

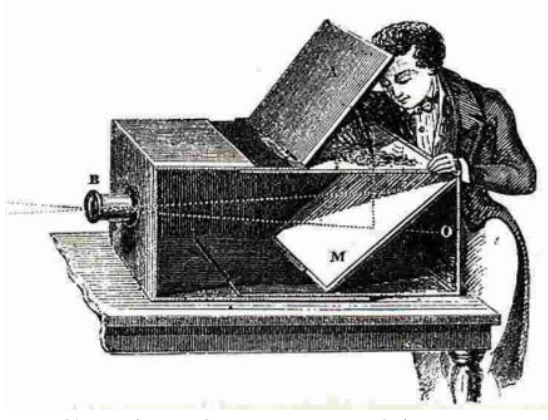

Gambar 3 Kamera Obscura

\section{Kamera Daguerreotype}

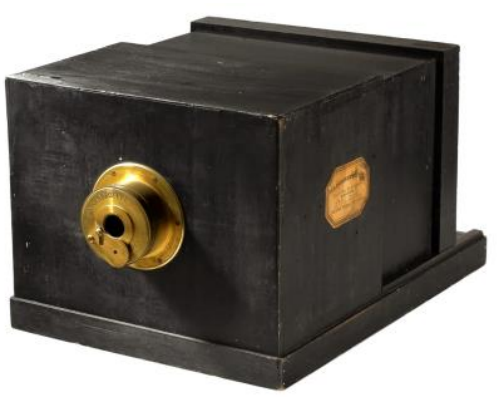

Gambar 4 Kamera Daguerreotype 
Kamera Polaroid

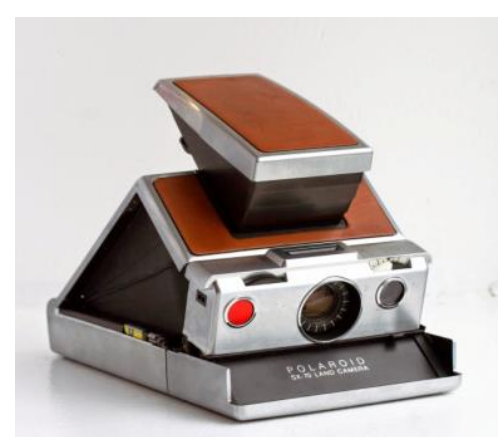

Gambar 5 Kamera Polaroid

KAMERA FOTO (STILL)

Compact Digital Camera

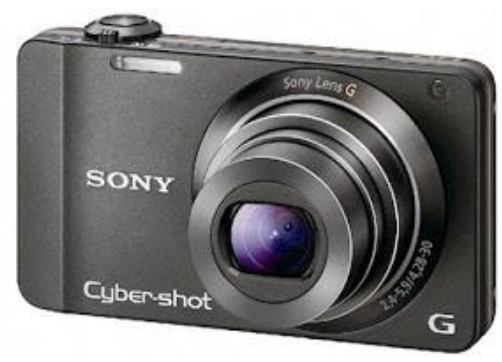

Gambar 6 Compact Digital Camera

\section{Kamera Prosumer}

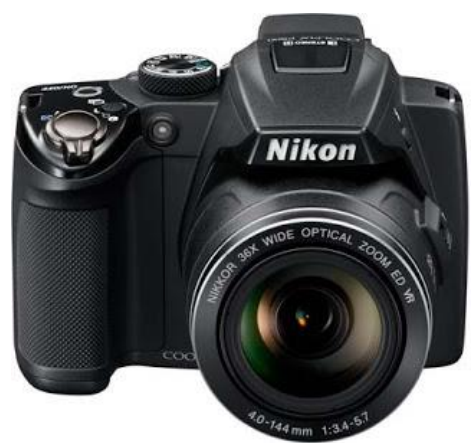

Gambar 7 Kamera Prosumer

Bridge Camera / DSLR

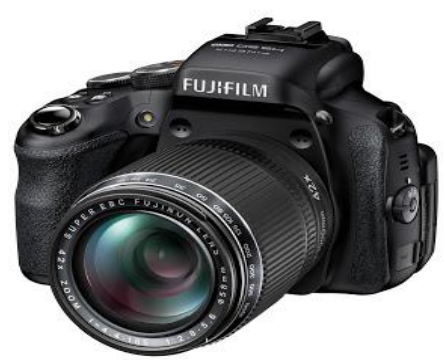

Gambar 8 Bridge Camera / DSLR

\section{Consumer Level DSLR}




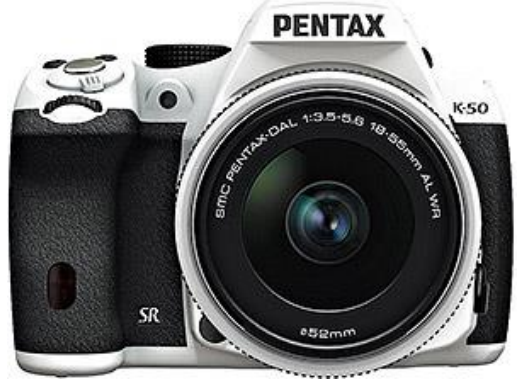

Gambar 8 Consumer Level DSLR

Mirrorless

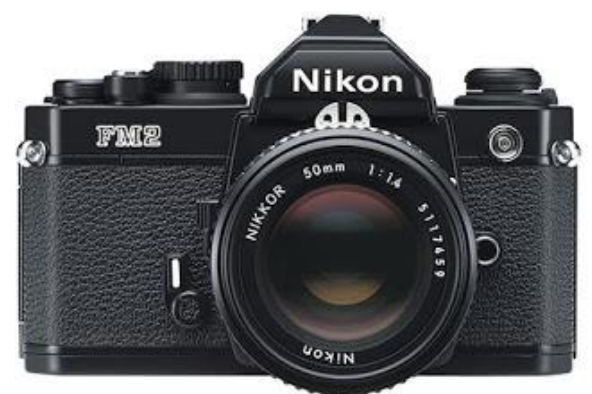

Gambar 9 Mirrorless

\section{Semi pro DSLR}

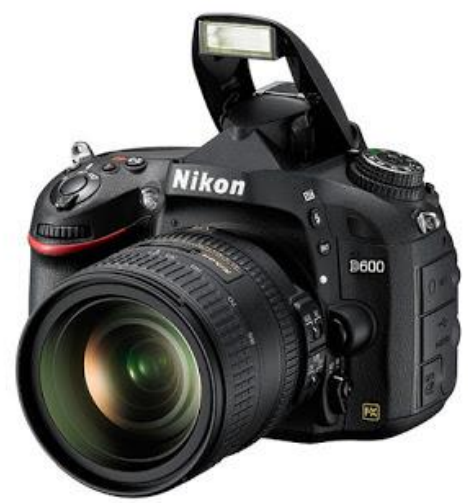

Gambar 10 Semi pro DSLR

\section{Boutique}

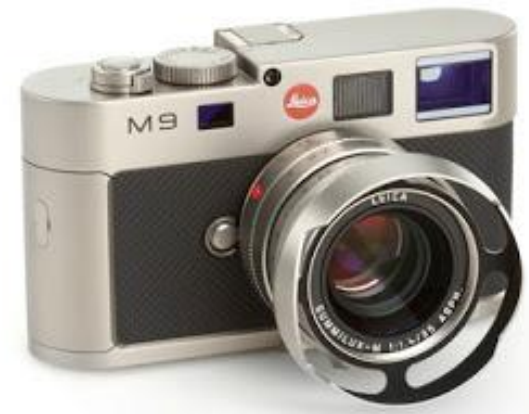

Gambar 11 Boutique

Medium Format/Professional DSLR 


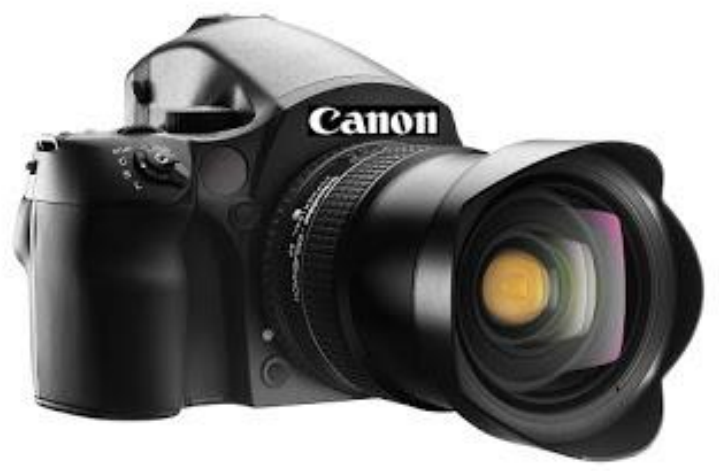

Gambar 12 Medium Format/Professional DSLR

\section{LITERATURE REVIEW}

1. Videografi: Kamera Dan Teknik Pengambilan Gambar. Di susun oleh D. Nunnun Bonafix. Jurusan Desain Komunikasi Visual, Fakultas Komunikasi dan Multimedia, BINUS University Jln. K.H. Syahdan No. 9, Kemanggisan, Palmerah, Jakarta Barat 11480. Kemajuan teknologi telah banyak mempengaruhi perkembangan film dan TV dalam decade terakhir. Artikel ini bertujuan agar para videographer mampu meningkatkan kemampuan dan keahliannya dalam menguasai alat kamera video serta menghasilkan karya yang inovatif dan artistik. Kamera, merupakan salah satu alat vital yang mengambil gambar video. Untuk menghasilkan gambar terbaik yang didapat, maka penguasaan kamera adalah menjadi hal yang mutlak. Mulai dari bagian-bagian kamera serta teknik pengambilan gambar. Dengan demikian, nantinya kemampuan semua videografer dapat meningkat dengan signifikan serta menghasilkan karya terbaik yang diakui.

2. Pengembangan Media Video Pembelajaran Tentang Pelajaran Videografi Kompetensi Dasar Gerakan Kamera Dan Jenis Pengambilan Gambar Pada Kamera Video Yang Layak Untuk Meningkatkan Hasil Belajar Siswa Kelas X Smk Pgri 2 Sidoarjo. Di Susun Oleh Arifin. Mengembangkan Media Video Pembelajaran Untuk Kompetensi Dasar Gerakan Kamera Dan Jenis Pengambilan Gambar Pada Kamera Video Untuk Kelas X Smk Pgri 2 Sidoarjo. Mengetahui Kelayakan Dan Efektivitas Media Video Ini Sebagai Media Pembelajaran Untuk Kelas X Smk Pgri 2 Sidoarjo.

3 Analisis Teknik Videografi Pada Iklan OLX Versi Mahasiswa Tingkat Akhir Dari Segi Teknik Dasar Videografi. Di Susun Oleh Fesi Gempar Wahyu Eko Prasetyo, Aripin, Auria Farantika Yogananti. Jurusan Ilmu Komputer Dan Desain Komunikasi Visual, FIK UDINUS, Semarang. Seiring Berkembannya Jaman Muncul Perusahaan Lain Yang Bermunculan Dengan Fungsi Yang Sama Khususnya Di Indonesia, Oleh Karena Itu OLX Harus Memiliki Strategi Salah Satunya Dengan Meluncurkan Berbagai Iklan, Contohnya Adalah Iklan OLX Versi Mahasiswa Tingkat Akhir ( Laptop Bimo Error ) Yang Ternyata Sempat Menjadi Iklan Dengan Rating Tertinggi Pada Situs Youtube Khususnya Pada Channel Resmi OLX, Masalah Disini Adalah Bagaimana Iklan OLX Versi Mahasiswa Tingkat Akhir ( Laptop Bimo Error ) Dapat Menjadi Salah Satu Daya Tarik Terbesar Walaupun Dengan Proses Videografi Yang. Hal Tersebut Menimbulkan Tanda Tanya Apakah Teknik Videografi Mempengaruhi Keberhasilanya. 


\section{DAFTAR PUSTAKA}

[1] Baskin, Askurifai. 2003. Membuat Film Indie itu Gampang Bandung : Grafindo

[2] Biran, Misbach Jusa, H. Teknik Penulisan Skenario (Diktat Kuliah). Diperbanyak Oleh Akademik Sinematografi Institut Kesenian Jakarta.

[3] Biran, Yusa Misbac. 1997. Kamus Kecil Istilah Film. Jakarta Yayasan Pusat Perfiman H. Usman Ismail

[4] Effendy Onong Uchjana. 1983. Televisi Siaran Teori\& Praktik. Bandung : Mandar Jaya

[5] Effendy Onong Uchjana. 1998. Dimensi - Dimensi Komunikasi Bandung : Alumni

[6] Englender, A. Arthur \& Paul Petzold. 1976. Filming For Television. New York : Hasting House

[7] Freddie, Young. 1980. Motion Picture. Terjemahan Asrul Sani. Jakarta

[8] Golman, Chuk. 2003. Digital Film Making Solutions, Solve Any Video Shoot or Edit Problem in 10 Minutes or Less. California : Mcgraw Hill 